\title{
Construction of Evaluation System for High Performance Scientific Research Team Based on Multi Value Elements Coupling
}

\author{
Jing $\mathrm{Gu}$ \\ Nanjing Institute of Tourism \& Hospitality \\ 2713254206@qq.com
}

Key words: Multi-value Elements, High Performance and Work Values

\begin{abstract}
This paper, taking high performance research team as the research object, puts forward a team performance evaluation system based on multi value creation elements and value evaluation, which will help to clear the team's common value goals, play the power and individual potential of the team, effectively integrate the team talent values, the team talent development, and help improve and protect the team. Holding high performance team value to improve the development level of higher education. Through the use of Delphy Fa, AHP, the "Nine Palace" matrix from the two dimensions of performance and values to explore the multi-value factors coupling evaluation system, through a "double-firs-class" university research team to carry out an example analysis, to verify its application and effectiveness in practice. The study found that the core of ensuring high quality scientific research team to produce high quality performance is shared work values.
\end{abstract}

\section{Introduction}

With the continuous growth of the scientific research team in universities, the functions of technological innovation, technological development, personnel training, and social services in China are effectively promoted. At present, China's higher education has been in the transition period from scale expansion to quality improvement. How to scientifically evaluate the scientific research team's performance, how to effectively improve the sustainable development ability of high-performance research teams and how to build a strong innovation ability and strong cohesion? The high-level and high-performance scientific research team has become an urgent issue to be solved in the scientific research management department and human resource management field.

From the existing research at home and abroad, the evaluation of the performance of the research team is mainly concentrated in the field of economics and management. Most of the evaluation methods are chart evaluation, alternation sorting, paired comparison, key event, behavior anchoring rating, behavior observation, balanced scorecard, etc. From the point of view of evaluation, the research on team performance evaluation originates from enterprise management. The research on team performance is mostly based on the enterprise, and the university scientific research team is different from the performance evaluation of other organizations, such as the enterprise, and has its unique characteristics. The content of the assessment must be comprehensive, requiring the objectives of the examination team, the academic value, the economic value, the scientific research ability and the comprehensive quality of the members. In the process of evaluation, it shows the characteristics of stages. Most scientific research teams are mainly project-oriented, and are used as the basis for evaluation. In the evaluation method, the former university scientific research team's performance evaluation mainly adopts the peer review method, and is insufficient in the evaluation accuracy and objectivity. Zhang Ali uses the team arrangement and the team members as the evaluation object, and uses the KP1 analysis method to design the four first grades of the academic 
value, the economic value, the social value and the talent benefit. The performance evaluation system of Shanxi University of Finance and Economics is taken as an example. Bao Hanli and others adopted the AHP legal system to determine the performance evaluation system of scientific research team with six dimensions: scientific research achievements, team cooperation ability, paper collaboration ability, paper work, achievement transformation and technology promotion, discipline construction and training talents. Jiang Jiao and others selected a high performance team to verify the performance evaluation system composed of seven dimensions, such as goal, authorization, relationship and communication, flexibility, optimal capacity, recognition and reward, morale and so on.

To summarize, , through combing the existing research, it has been found that the performance evaluation of scientific research teams in universities in China is mostly based on scientific research projects, the number of three major papers retrieved, scientific research results, and research and development of science and technology as performance evaluation indicators . There is still much room for research on the research of the research team in the field of performance evaluation.First, the identification and characteristics of high-performance research teams are uncertain.Second, the evaluation indicators and methods lack scientificity. The third is the disconnect between theory and practice.

Based on this, this paper mainly clarifies the concept and characteristics of high-performance research teams, and then combines the practice of scientific research teams in double-firs-class universities to construct a systematic and integrated high-performance research team from the perspective of multi-value elements. Through the introduction of the system's design ideas and basic logic system, it is hoped that this system can be used for reference by the scientific research management department of universities and colleges, and will complement the theory.

\section{The identification and Characteristics of High Performance Research Teams}

First of all, we should clarify the concept of a high performance research team. The high performance scientific research team is a scientific research community, which is composed of the university related scientific research personnel in universities under the collective leadership of the outstanding leaders. It has a scientific research community with distinctive features such as university-level sexuality, strong stability, high performance, management standards, and high efficiency(Sun Xiaoke ,2011).

Based on this, the concept category of the high performance research team includes the following modules: First, the common work values (why do the research); Second, the criteria of the team evaluation (in what dimension to evaluate); Third, the tools of the team evaluation (Assessed by what kind of tools and methods) Fourth, several modules such as the team's sustainable development (how to achieve individual and team precision, customized growth and sustainable development), and these four parts are mutual influence and mutual Contact organic whole.

\subsection{Analysis on the characteristics of scientific research team in Universities}

First, the goal of university scientific research team is different from the expected goal of scientific research project. It can determine the keynote and direction of a group. The research team takes a lot of time to explore and form a common and clear target that is relatively stable in the short term. This goal not only belongs to the entire scientific research team but also belongs to everyone in the team. Once the target is established,,it forms an internal drive. With the team 
members' recognition of the team organization, the team's values and ideas will be perceived as more unique, distinctive, and positive. These more active perceptions will lead to higher levels of team member loyalty and to the organization and its Cultural commitment.

Secondly, the responsibility of the research team should be a first-rate academic leader. The academic leader is the soul of the university's scientific research team,.It has certain academic status, academic prestige, and academic reputation, and has achieved certain achievements or academic achievements in its research direction. And it has attractive, united, and agile people's conduct and charisma.

Third, professional knowledge and skills are the basis for the establishment of a scientific research team. The skills required by the scientific research team include professional knowledge and skills, problem-solving skills, and interpersonal skills.

Fourth, the strong cohesion of the scientific research team arises from a good academic environment. Universities should create an academic atmosphere of tolerance, a democratic academic atmosphere, a relaxed academic environment, and an interpersonal environment. Meanwhile, high-performance research teams also leave the micro-environment of equality, cooperation, and communication. Every member of the research team should communicate in an atmosphere of equality, only the colliding of different academic views. . Only in this way can we generate sparks of wisdom and find out the technical means and methods to solve project problems.

Fifth, the long-term nature of the research team. The scientific research team in universities should be characterized by persistence and closeness, and it can carry out in-depth and continuous work around relevant research directions.

\subsection{Standards and Tools for Team Evaluation}

The standard of team evaluation is the scale of team performance measurement, and the standard can be used to accurately measure team performance. Generally speaking, the value of a team refers to the attributes of a team as a main body satisfying the needs of the object (society and others).

Based on the existing research, according to different classification criteria, the dimensions of team value evaluation include personal value, team value, social value and realistic value. According to the criteria of team performance evaluation, how to use the standard to evaluate the team is the problem of the team performance evaluation tools and methods, the team evaluation methods commonly used in the Analytic Hierarchy Process, fuzzy comprehensive evaluation method, , regression analysis), etc.

\subsection{Sustainable team development}

The evaluation of team performance is a systematic process, whether it is common values or the evaluation process of team performance is a circular work.

The core of team evaluation is not "evaluation", but also "measurement". The core is team work values. Based on this, this paper also takes the sustainable development of the team as an organic plate into the team evaluation work category, and expounds its related mechanism and system.

\section{The Evaluation System of High Performance Scientific Research Team Based on Multi-Value Elements Coupling}

On the basis of reviewing and commenting on the evaluation of traditional research teams, a high-performance research team evaluation system based on the coupling of multi-value elements is proposed. From the perspective of talent management value chain, system theory, attachment theory, 
coupling theory, social promotion theory, Social identity theories and other related theories are applied to the high performance. The core work values evaluated by high-performance research teams, emphasizing multiple dimensions of competence, contribution, value pursuit, and personal growth.

\subsection{Analysis and construction of evaluation system}

According to the theory of systems theory, the elements determine the structure and the structure determines the function. To make use of the function of the human resources value evaluation system, it is necessary to establish a reasonable structural system among various value elements to ensure the effectiveness of the system.

(1)The evaluation system of high performance scientific research team includes the interrelated and complementary relationship between each subsystem, forming an organic whole.

(2)The value chain of human resource management is based on value creation, and forms a closed loop through value evaluation and value distribution. The coupling of different value elements together leads to the difference in value creation. Precise accounting of such differences can provide a foundation for value evaluation and value distribution.

(3)The evaluation system of human resources includes the standard of evaluation and the tool of evaluation. Only by clarifying the criteria of evaluation can the effective evaluation work be followed, and the method used in the evaluation process is the evaluation tool.

\subsection{The basic framework and core content of the multi-value element coupling system}

The multi-value element coupling evaluation system is based on the management theory of the talent value chain, and comprehensively uses the elements of the high-performance research team to evaluate and integrate each other to form a set of high-performance promotion strategies. Considering the reliability and validity of the evaluation system, when determining the contents of the team performance evaluation indicators, multiple methods are used simultaneously, and the same measurement method is used to ensure that the results of the team performance evaluation index contents are the same and the stability of the team performance evaluation indicators is ensured. Sex and consistency can accurately reflect the actual work efficiency and results of the members.

\subsubsection{Multi-value elements coupling system in the management of scientific research teams in} Universities

The mult-value element coupling performance evaluation system is based on the theory of value chain management. It integrates all the elements of the evaluation of organizational value and forms a set of talent efficiency promotion system. The team performance evaluation index system focuses on the overall quality and level of scientific research of the team, so team performance is regarded as the object of performance evaluation.

The first is to optimize the composition of scientific research teams. Establish team plans by establishing team members and clarifying team goals. The second is to strengthen the output of high-quality scientific research results. The third is to deepen the university's incentive system. Incentives are the means, not the purpose, and the real purpose is to enhance the long-term development of the school. The fourth is to refine the team members' growth system and development path.

\subsubsection{The basic framework of multi-value element coupling system}

The basic framework of the multi-value element coupling system includes "one core, three 
systems, and five major projects."

\subsubsection{One core}

The core elements of high performance research team are team values, including common values, attitudes, contributions and abilities. These factors can be attributed to different qualities, such as contribution to achievement, including creation of individual performance and creation of synergistic performance.

\subsubsection{Three major systems}

On the premise of a clear understanding of the structure and connotation of team work values, this paper analyzes the impact mechanism of team work values on team performance based on the structure of team work values. Team work values, composed of team building factors, interpersonal factors, self actualization factors and material environmental factors, determine team behavior to a great extent, and team behavior is the direct influence factor to achieve team goals and achieve high performance.

The so-called three systems are a set of performance evaluation systems based on the logic of "team values, team evaluation, and team development". This article has elaborated the relationship elements and quality points of the team work values.and then coupling the common values elements, and forming different value evaluation matrix to form the "values performance" evaluation matrix by two latitudes of values and performance.

\subsubsection{Five major projects}

The five major projects include evaluating team goals, evaluating individual standards, evaluating individual tools, performance and salary systems, and sustainable development. On the one hand, we must protect the interests of the team members, and also pay attention to personal growth and promotion.

Application of multi value element coupling evaluation system: evaluation of a "double first class" scientific research team

Select the research object

A university was designated as a national key university by the State Council in 1978; it became one of the first universities in China to have the right to confer doctoral degrees after approval by the State Council in 1981; it entered the national "211 Project" construction in 1996; it was approved by the Ministry of Education in 2000 to establish a graduate school; in 2011, it became a key construction university for the "985 project superior discipline innovation platform"; in 2017, it entered the national "double first-class" construction sequence.

Since the establishment of the school, it has trained more than 16000 of senior specialized talents for the state. Among the alumni, there are 14 academicians, dozens of provincial and ministerial leading cadres and generals, as well as a large number of famous scientific and technical experts and management experts. The school is committed to cultivating high quality citizens and future pioneers, constantly advancing the reform of education and teaching, and gradually set up a training system for innovative talents with the characteristics of South China Airlines, and has achieved a number of high-level teaching achievements.

A total of 18 national teaching achievement awards; 6 national outstanding doctoral dissertations, 15 nominations for national outstanding doctoral dissertations, 11 national-level exquisite courses, and 6 national quality video open class construction projects. There are 5 national-level excellent teaching teams, 6 national-level specialty specialties (construction points), 8 key specialties of the Ministry of Industry and Information Technology, and 7 major national defense majors and 
short-coming majors (directions). It plays a major role in supporting national innovation-driven development strategies, serving economic and social development, promoting the fine traditional Chinese culture, cultivating and implementing the core values of socialism, and promoting the connotation of higher education.At the same time, there are also some problems in the construction of a double class university:

One ,how to formulate a common work value system formed by the team, and pass on it and develop it.

Two, if effective, targeted evaluation of the value of team members, what kind of effective promotion path should be adopted?

Three, how to give the team core talent certain rewards and maintain the stability of the team?

\subsection{Research process}

The goal of the energy, environment, economics and policy research team of the double class universities is to continuously provide high-quality achievements and high-end talents in the field of energy and environmental policy.In the aspects of scientific research, cooperation and exchange, personnel training, social services, cultural heritage and innovation. All have made a series of outstanding progress and formed a good development trend.

The common values formed by the team are "major issues-oriented, based on exchanges and cooperation, continuous innovation as the driving force, and diligence and practicality as the work style", and initially established an efficient, orderly, coordinated development of the organization and management system.

Combining the core values and development goals of the team, the team is evaluated in terms of both work value and performance dimensions. Each dimension was divided into three levels and divided into nine compartments to represent different levels of combinations in two dimensions, in two dimensions. The evaluation index can be determined according to different conditions.

The performance depends on the external factors related to the team, such as scientific research, scientific research and academic contributions, which are usually divided into three grades of high school and low level. Because of the large number of external factors, what are the key factors to be identified and to evaluate the performance of the team. The value of work depends on team building, team building, interpersonal relationship, self realization and material environment. It is usually divided into three grades of strong and medium strength. Because of many internal factors, the team also needs to identify what are the key factors and finally put forward multiple value elements and critical valuation factors, which constitute one of the nine factors. A quadrant of a matrix.

\subsubsection{Value Element Coupling and Performance Evaluation of "Nine Palaces" Matrix Team}

The "Nine Palaces" matrix uses more factors to measure the two variables of value and performance. On the vertical axis, multiple indicators reflect performance; the horizontal axis uses multiple indicators to reflect work values and evaluates the existing scientific research teams through these two dimensions, each dimension is divided into three levels, and nine may represent the combination of different levels in two dimensions. Then determine the evaluation indicators according to different situations.

When drawing a matrix, you need to find out the external (performance) and internal (work value) factors, and then weight the factors to derive the standard for measuring internal and external factors. This is of particular importance to the scientific research team of higher education institutions in promoting personnel training, scientific research, and social services.

To determine the object of evaluation, analyze the internal and external environment of each 
scientific research team, divide the type of research team according to the actual situation of the scientific research team, and conduct an internal and external environment analysis for each research team.

Delphi method was applied to the importance of the selected key factors, remove the low importance factor, and finally determine the key factor. Determine work values and performance as the main evaluation indicators, and the weight of the first indicator. The core values are mainly consist of value psychology, value recognition and value evaluation. Performance consists of leadership ability, team cohesion, team learning ability, and scientific research achievements. Determine the weight of each evaluation indicator while determining the indicators.

Analyze the key factors using AHP. According to the expert rating, the core values and performance of each research team are evaluated and scored, and a weighted sum is obtained to obtain the final score of the first indicator.

Each evaluation indicator is marked on the Jiugong lattice matrix. According to the scientific team's values and overall performance scores, each research team is circled on the Jiugong lattice matrix. When labeling, note that the size of the circle represents the overall level of performance of its team.

According to the position of each evaluation factor on the ninth palace matrix, the scientific research teams are explained and explained systematically.

\subsection{Evaluation of the effectiveness of scientific research teams in universities}

Team $\mathrm{A}$ is at a relatively high position in terms of values and performance. This high performance is also attributed to the fact that the overall characteristics of the research team's evaluation system construction are clear goals, efficient work, and strong social influence. Under the supervision of the scientific research management department, After three years of completion of the team's goals and tasks, the university's talent management has been rapidly promoted and developed under the multi-valued element coupling system, which has created a double-first-class university for the school and has also enhanced the social and economic development and knowledge building. support. However, there is still a need for further improvement in terms of cultural heritage and innovation and the social impact of expected results.

University scientific research team is an important development platform for gathering high-level talents and developing high-level achievements. Scientifically and reasonably evaluating the performance of scientific research teams in universities is an important part of scientific research team management, which is conducive to the improvement of team management skills and team innovation capabilities. The improvement of capabilities is of great significance. Through the accuracy, integration and overallity of the multi-value factor coupling evaluation system, the effectiveness of the research team management is improved from the perspective of values, and the value of the elements is taken as the core to form value unification, value creation, value evaluation and value. Assigned as the system's human resources management model. Applying the concept of knowledge value to the practice and active exploration and practice of human resource management in universities has good practical value and promotion significance.

\section{References}

[1] Wuwei L I, Chang B. Research on the Evaluation Factors of Venture Capital Management Team Based on Interpretative Structural Model[J]. Journal of Fudan University, 2018.

[2] Shen L. Research on evaluation system on university sports team management[C]// IEEE, 
International Conference on Communication Software and Networks. IEEE, 2011:766-769.

[3] Cao Y. Based on the Performance Evaluation System of Strategic University Innovation Team Building Research[J]. Education Teaching Forum, 2017.

[4] Zhang J A, Wang S. Construction of Evaluation System of Intrinsic Academic Productivity of University Scientific Research Team[J]. Research in Educational Development, 2012.

[5] Wang H T, Zhao W Q, Dai X L. Design and Implementation of Evaluation System for Firm Research Team Leader's Performance[J]. Computer Programming Skills \& Maintenance, 2013.

[6] Zhao S D, Li S H. Research on System Evaluation of Top Management-Team Based on the Method of Analytical Hierarchy Process and Rough Set[J]. Applied Mechanics \& Materials, 2011, 63-64:322-326. 